\title{
Why medicine inspires me
}

Lee Goldman, Parveen Kumar, and Bob Souhami are responsible for some of the most inspiring medical textbooks used by doctors today. So what inspires the inspirers? We asked them to tell us

\section{Better evidence, improved care}

Columbia

University Medical

Center, Columbia

University, New

York, NY 10032,

USA

Lee Goldman

executive vice

president for health

and biomedical

sciences

lgoldman@

columbia.edu

BMJ 2006;333:1320-3
As is hopefully true for all doctors, I am inspired by the opportunity to spend my professional lifetime trying to improve the health and welfare of humanity. How to achieve that goal is intensely personal, however. In deciding to be a clinical investigator, teacher, and, more recently, a medical administrator rather than a full time clinician, my inspiration goes beyond the desire to help individual patients in a series of one-on-one encounters. I believe that individual doctors can become an even more powerful force when they are informed, educated, stimulated, and even moulded to benefit from collective knowledge and to raise their standards of performance. Nevertheless, my decision to maintain in active clinical practice underscores the recognition that these other activities have little merit unless they can be transformed by practitioners into improvements in patient care.

While in medical school I made the unusual decision simultaneously to pursue a masters degree in public health. My peers on each side were equally perplexed. The medical students and medical faculty saw public health, at least in the United States, as largely outside the realm of real patient care. My public health colleagues saw doctors as unable to recognise the big picture of what truly influences the course of human health. I vacillated between being hopelessly discouraged that the two sides would never meet and hoping that a potentially powerful alliance could be forged if these professional neighbours could come together.

During my subsequent clinical training, I was privileged to train at several top US medical institutions. At each, I was struck by the influence of local experts, veritable gurus whose powers of deductive reasoning established them as the local wise ones. Their opinions were followed loyally and sometimes even blindly by trainees, especially in their areas of expertise, but often also beyond those areas. Expertise was attributed to wisdom, which was based on experience and cumulative observations over time as well as the logic and persuasiveness of the thought

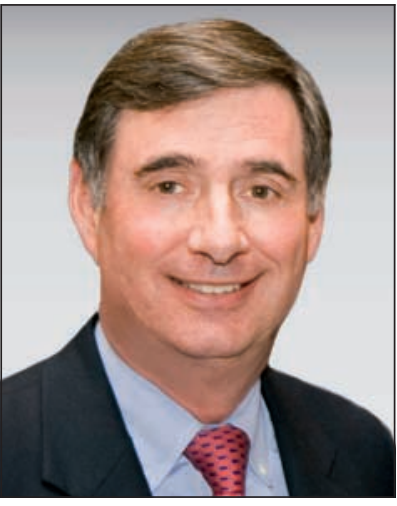

Lee Goldman processes. Unfortunately, there was little or no recognition that these expert opinions depended on all the biases inherent in uncontrolled observations. What I found most striking was that their experiential wisdom became dogma in their local environment, yet that same opinion could be heresy at an equally prestigious institution where the deductive powers of another experienced local leader led to different conclusions.

Despite my degree in public health, I always believed that no higher calling existed than to help individual patients.

\section{Biography \\ Lee Goldman is the Harold and Margaret Hatch professor and executive vice president for health and biomedical sciences at Columbia University, where he also serves as dean of the Faculties of Health Sciences and Medicine at Columbia University Medical Center. Before joining Columbia, he was chair of the Department of Medicine at the University of California, San Francisco and a professor at Harvard. \\ His research has focused on the effectiveness and costs of diagnostic and therapeutic strategies, with special emphasis on how the delivery of medical care can be improved by the results of high quality clinical investigation. His work at the interface between "public health school methods" and clinical medicine is exemplified by the "Goldman index" to predict the cardiac risk of non-cardiac surgery. \\ Lee Goldman is a past editor of The American Journal of Medicine, and he is currently the lead editor of the Cecil Textbook of Medicine and co-editor of Hospital Medicine and Primary Cardiology.}

However, such a goal was not possible if the wisest experts could not agree on the most fundamental issues. This knowledge gap inspired me to pursue a career that would focus on developing better evidence so that expertise in medicine would be based on true science rather than pseudoscientific deduction. The best doctors would understand the evidence and create systems in which decisions incorporated that wisdom, always adapted to the individual characteristics of the patient at hand. My aspiration became to perform research that would meet this standard.

During my training as a cardiologist, both my inspiration and my aspiration were reinforced by an offhand comment that influenced me greatly. As a group of leading American cardiologists were recommending the addition of quinidine to digoxin for a patient with heart failure and atrial fibrillation, a foreign trainee, who had come to the US to learn our advanced technology and take it back to his home country, blurted out, "Everybody knows that the combination of quinidine and digoxin kills people." Suddenly it became clear to me that the disparity between what is classified as dogma in one institution but heresy in another did not occur in the US alone, but was an international phenomenon. Years later, data confirmed that adding quinidine to digoxin kills people, that neither drug is particularly efficacious, and that each has substantial side effects. For heart failure, drugs such as digoxin that increase the performance of individual cardiac myocytes are of surprisingly little value and often are deleterious. For arrhythmias, drugs such as quinidine that suppress aberrant beats make the electrocardiogram look better but often worsen 
prognosis. In theory, everything I was taught as a cardiology fellow about the treatment of heart failure complicated by atrial fibrillation seemed logical: get the myocytes to work better and suppress the arrhythmia. In truth, however, all of it was wrong. The inspiration was that deductive reasoning may be dangerous. The aspiration was reinforced: help physicians to gather, interpret, and use evidence more appropriately.

As my career progressed, that aspiration-to spread the word about the difference between deductive reasoning and medical evidence-became inspiring as well. I had the privilege personally to supervise dozens of trainees who have gone on to distinguished careers gathering and interpreting medical knowledge and, as a result, improving the health care of populations and of individual patients in one-on-one care. I have also organised training programmes that have educated more than 1000 young doctors from all over the world. I am inspired every day by what they have accomplished collectively and by the multiplicative effect as they themselves become leaders and teachers of others. These professional descendants and many others like them have helped medical care advance, with epidemiology guiding basic science, basic science breakthroughs generating new treatments, new treatfrom randomised trials influencing systems of care.

Now, this manifest impact on medical knowledge and practice has generated for me a new series of aspirations guided by the same inspiration. I am inspired by the hope that medical education can be changed, the delivery of medical care can be improved, and my one-on-one encounters with my own patients will result in better outcomes. In this way, the seemingly divergent skills and perspectives that I learnt as both a medical student and as a student of public health will converge in improvements in the health and welfare of populations and of individuals.

doi 10.1136/bmj.39058.497060.BE ments being evaluated by randomised trials, and data

\section{The greatest joy: the patient's thanks}

I find it hard to look back and capture what initially inspired me to take up medicine, but I think that my aspirations are still the same. Medicine is a "way of life" and combines that rather nebulous feeling of wanting to help and care with the more exact principles of science and logical thought. After all these years as a doctor, I still want to get out of bed and go to work in the mornings. Despite all the cutbacks, targets, organisational problems, and increasing workload in the National Health Service, the patients are still there. Doctors are at the top of the list of professions that the public thinks are worthy of "respect" and also are "most likely to tell the truth," and this makes me feel privileged to be a doctor. There is no place for arrogance or self satisfaction-the days of Sir Lancelot Spratt are hopefully far gone.

Clinical medicine still holds many challenges. Although many clinical problems are easily diagnosed I still relish a diagnostic conundrum that calls on all my faculties and training to tease it out. Like a Conan Doyle detective story, there is much satisfaction in getting it right and, of course, much frustration in not. I have worked in the east and north ends of London for most of my career, and I have been fortunate to treat people from different ethnic groups with different cultures, beliefs, and diseases. This has been a humbling experience but also educational and fascinating. Not only do I see diseases from all around the world, but I see how the expression of these diseases and the anxieties they generate vary in different ethnic groups.

Medicine offers a huge variety of choices-clinical ment-to name but a few. I have always found that combining clinical work with these other disciplines helps keep mesane.

Sir Anthony Dawson at Barts hospital inspired my choice of gastroenterology as a specialty, and the Dawson and Clark team attracted many a young aspiring researcher. My major research interest has been coeliac disease, and I have enjoyed being part of an work, research, teaching, training, and manage-

\section{Biography \\ Parveen Kumar is professor of clinical medical education at Barts and the London School of Medicine and Dentistry, Queen Mary College, University of London and honorary consultant physician and gastroenterologist at Barts and the London NHS Trust and the Homerton University Foundation Hospital \\ NHS Trust. After qualifying from Barts, she trained as a gastroenterologist and completed an MD in coeliac disease, which remains her chief research interest. \\ Together with Michael Clark she edits Clinical Medicine, a textbook for students and doctors. She was the academic vice president and senior censor of the Roval College of Physicians from 2003 to 2005 and previously its director of continuing professional development from 1999 to 2004. She chaired the Medicines \\ Commission UK from 2002 to 2005, and she has served on the boards of NICE, and Barts and the London NHS \\ Trust. She is currently president of the British Medical Association.}

international fellowship researching into this condition. I did my research postgraduate degree under the supervision and mentorship of Michael Clark, who later became my coeditor and coauthor.

So why Clinical Medicine? The need for Kumar and Clark's Clinical Medicine was inspired by the desperately boring textbooks I read when I was a medical student. They were devoid of pictures and algorithms and consisted of page after page of verbose, ambiguous, and unstructured text. Michael Clark and I wanted to make learning more approachable, interesting, and above all fun. This book changed the face of medical publishing and made pictures, colour, and bullet points more accept-

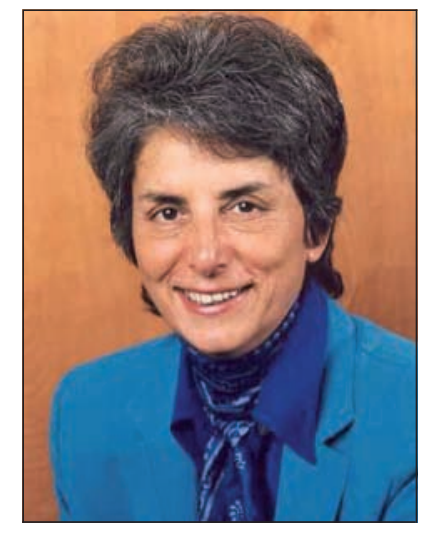

Parveeen Kumar
British Medical Association, Tavistock Square, London WC1H 9JP Parveen Kumar president

pkumar@bma.org.uk 
able in a "serious" book for professionals. Mike and I are grateful, but humbled, by its enormous success, as it brings with it the responsibility of keeping it (and ourselves) up to date. It was written and edited during holidays, evenings, and weekends (valuable time snatched from our long suffering but supporting families) and is constantly at the back of our minds. Our hardworking authors, colleagues, students, and young doctors provide continuing support and help and, of course, our readers provide extremely valuable advice and criticism.

Medicine is currently undergoing many changes. The medical curriculum has changed almost beyond recognition since I was a student. More emphasis is placed on communication and clinical skills, but I am saddened that the basic sciences have almost been forgotten. Students are still trying to learn the 10 causes of, for example, clubbing, when they should really be asking questions about the mechanisms. An understanding of the basic sciences would be much more helpful for elucidating a diagnosis than memorising long lists. The practice of medicine has also changed with advances in technology and the discovery of the actual cause of a disease at a molecular level. All very exciting for an enquiring mind, but we need to change our practice to accommodate these modern changes.

So, medicine is still for me. The greatest joy is that simple "thank you" as the patient walks out of the door. Isn't it great?

doi 10.1136/bmj.39062.411875.80

\section{The certainty that we will know more}

University College London,

WC1E 6 BE

Robert Souhami emeritus professor of medicine

(robert.souhami@ btinternet.com)

Medicine is based on altruism, science, and human interest. Like most medical students, this is what attracted me and it still does. The aim is to preserve the good health of individuals and the general population. The aspirations are of excellent care, progress, and change. I find the continuing movement, and certainty that we will know more, inspirational and energising. Medicine is remarkable in its clinical and scientific breadth and its fusion with other disciplines and interests. Much of medicine grows from basic biology, but medical research and practice is also linked to physics, chemistry, statistics, population science, sociology, and politics. It's remarkable, for example, that new technical platforms allow quick identification of genetic patterns that in future may influence treatment given to individual patients and that this, in turn, will raise ethical and political issues for society at large.

Whatever interests and personality you have, there is probably an aspect of medicine to suit you. The diversity can be confusing for a student and young doctor thinking about a career. When I qualified I didn't know what would be the best path to choose. I quickly found that I would get most satisfaction from clinical medicine.

Throughout my career I have met clinicians and scientists who have set the standards that I wanted to achieve. I trained for eight years in internal medicine, much of it at University College Hospital London, where I came across outstanding

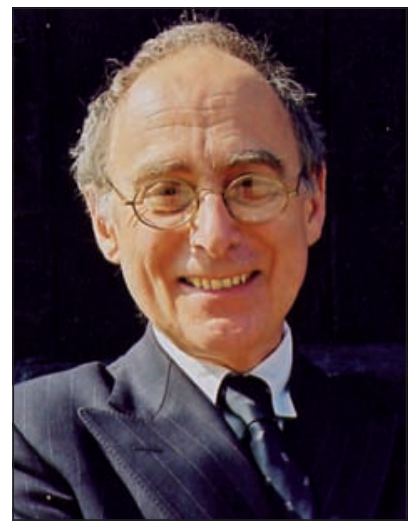

Robert Souhami clinicians and clinical investigators. The process of diagnosis, lacking modern imaging and molecular techniques, was much less certain then. The therapeutic options were also much more restricted, but the process of making decisions that were in the patient's interest was the same then as now. This clinical approach, based on experience and judgment, has been my main inspiration and has greatly influenced my academic career, both in teaching and in research.

As a student, I was sometimes defeated by explanations of signs,

\section{Biography}

Robert Souhami was appointed physician and senior lecturer in medical oncology at University College London in 1975. In 1987 he was appointed to the Kathleen Ferrier chair of cancer medicine at University College London. Ten years later he became dean of University College and Middlesex Medical School and subsequently principal of the newly formed Royal Free and University College Medical School. In 2001 he became director of clinical research at Cancer Research UK.

He created the first unit in the United Kingdom for the specialised care of adolescents with cancer and co-founded the London Lung Cancer Group. He chaired the cancer therapy committee of the Medical Research Council. His laboratory research has been into how drugs bind to DNA. He has edited or coauthored Tutorials in Differential Diagnosis, Textbook of Medicine, Textbook of Oncology, and Cancer and Its Management.

symptoms, and mechanisms of disease that didn't seem to make sense-at least to me. Later, I realised that words like "idiopathic" or "functional," often used as if they meant something other than ignorance, were useless. It seemed to me that good teaching would own up to, and demystify, lack of understanding. I think that a good teacher knows in advance what a student might find difficult and takes care to make things clear. We are lucky in the quality of our medical students in the United Kingdom. I enjoy teaching clinical medicine and this has led to writing textbooks, with others, aimed largely at undergraduates. I can't say that I find writing enjoyable or inspirational, but having to express difficult concepts with clarity sharpens up your thinking. Teaching and training are essential components of medicine. Brilliant lectures and articles and new discoveries and ideas are great rejuvenators.

I came to my specialty, medical oncology, as part of internal medicine. Cancer medicine has been a constant source of inspiration. Few areas of medicine demand the same degree of technical expertise and human understanding. Treatment of cancer by medical means was only just beginning 35 years ago. Over the 
years, increasing intensity of treatment and more accurate diagnosis have meant that clinical judgment remains just as important, but the emphasis has changed towards the understanding and exploitation of new diagnostic and therapeutic methods. Advances in understanding the process of cancer development have been astonishing, and have come from the technical virtuosity of modern molecular biology. The conceptual framework has been transformed and with it the possibilities of new treatments that are now emerging.

The constant development of new approaches is engrossing. In cancer medicine how far should new pathological classification and precision change practice? Who will benefit from new treatments and who might be harmed by them? How will an early diagnosis through screening change the advice you give to the patient in front of you? The rapid increase in knowledge necessitates continued learning through specialist publications, meetings, and congresses. Like everyone else, I had to abandon the breadth of the generalist to become specialised in a much narrower area of medicine. I regretted this, and I still do. You become technically expert in the area you know about, but you risk losing the balance and judgment that a wider interest brings.

This leads me to the last main source of inspiration and that is medical science. My academic work has had two components. The first has been therapeutic research, especially in lung cancer and sarcoma, largely based on large scale randomised therapeutic trials. The trials have brought together investigators in different countries, statisticians, clinicians, nursing specialists, and pharmacists. They have raised issues in medical ethics, data interpretation, and monitoring and have greatly improved the standard of what can be considered to be reliable evidence. The results of some of these trials have changed clinical practice and improved management. The second component has been laboratory work. Here I have had the benefit of working with exceptionally able scientists. As an academic clinician I don't expect to be working at the bench for many years or much of the time. Of course, you need to understand the techniques and their limitations. The partnership comes in the direction and focus of the work and its relevance to cancer. Knowledgeable clinical scientists have much to contribute in this respect. Conversely, knowledge of the limitations of the laboratory science prevents naive or over-optimistic interpretation of new findings in clinical research-a recurring problem in cancer management. It's a great career. Given the chance I'd start all over again.

doi 10.1136/bmj.39062.508067.80

\section{Living conditions}

\section{David Loxterkamp}

Do you see him sitting there? He broods over us from the examination table, his body language singing its silent demands. Eyes riveted down, I fumble through a formidable chart. My eye catches a spinal scan mangled by surgical artifact, an allergy list to every drug except schedule II analgesics, and half hearted reports from half hearted visits to a dozen different specialists. Must we bother with the examination? Both of us know the nature of the contest. Would I mind refilling a prescription that my partner already conceded? Could I complete disability papers that will provide support for his wretched living conditions? $\mathrm{He}$ winces. I posture. We are doomed.

Yet in the vagaries of our impasse lie what lured me to medicine. Let the patients with sore throats and urinary tract infections and those with metabolic syndrome taking 15 prescription drugs and on standing orders have their measurable outcomes, their chronic care plans. I stalk a more elusive prey-crumbs of happiness displayed for me, a view from the verge of change. Tell me of these, brother. You can trust me with their insignificance.

\section{Lay of the land}

I live in a small town on the coast of Maine. It takes no more than 35 minutes to jog the periphery of my community, two minutes to bicycle from hospital to home, 30 seconds to round the well trod hallways of my office.
None of us here is going any place, anyway. Here I have settled in, made a home, learnt to limit the burdens that agitate my sleep, and attend to what matters for those who matter to me.

In 22 years of patient care I have made my own bed. I have established or accepted the conditions for my success. They are not what I grouse about at medical staff meetings or boast about among friends. No, clinical guidelines and insurance forms are merely the crust over meatier matters. Patients are people, which is something more than a meal ticket or an obstacle to "having a good day." They are neighbours, team mates, and fellow parishioners. Their misfortunes ripple through the organism of our community. Through a hundred handshakes and self limited illnesses they have earned the audacity to say, "You are more than my doctor; you are my friend." It is their call.

The conditions that shape my professional life are geographical, where every street corner and public market holds a flash card for a moment of mistaken judgment, clinical oversight, or verbal blunder. As with most doctors in primary care, my need for approval and gratitude has impaired my ability to say no or to concede the battle lost to disease. Conditions are also economic, forcing me to see more patients on a given day than I can do justice. It is the pace I negotiated for the salary I feel I deserve. I am conditioned by human nature, which makes it easier to report a positive biopsy 